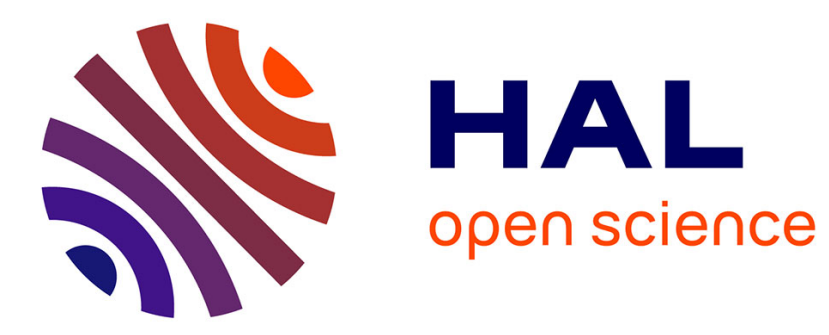

\title{
Phase separation, rheology and microstructure of micellar casein-guar gum mixtures
}

S. Bourriot, C. Garnier, J.L. Doublier

\section{To cite this version:}

S. Bourriot, C. Garnier, J.L. Doublier. Phase separation, rheology and microstructure of micellar casein-guar gum mixtures. Food Hydrocolloids, 1999, 13, pp.43-49. 10.1016/S0268-005X(98)00068X . hal-02694960

\section{HAL Id: hal-02694960 \\ https://hal.inrae.fr/hal-02694960}

Submitted on 1 Jun 2020

HAL is a multi-disciplinary open access archive for the deposit and dissemination of scientific research documents, whether they are published or not. The documents may come from teaching and research institutions in France or abroad, or from public or private research centers.
L'archive ouverte pluridisciplinaire HAL, est destinée au dépôt et à la diffusion de documents scientifiques de niveau recherche, publiés ou non, émanant des établissements d'enseignement et de recherche français ou étrangers, des laboratoires publics ou privés.

$$
\text { Copyright }
$$




\title{
Phase separation, rheology and microstructure of micellar casein-guar gum mixtures
}

\author{
Sophie Bourriot, Catherine Garnier, Jean-Louis Doublier * \\ Laboratoire de Physico-Chimie des Macromolécules, INRA, BP 71627, 44316 Nantes Cedex 3, France
}

Received 12 January 1998; accepted 10 July 1998

\begin{abstract}
The properties of micellar casein + guar gum mixed systems have been investigated at $20^{\circ} \mathrm{C}$, pH 7 and in $0.25 \mathrm{M} \mathrm{NaCl}$; in these conditions, the mixtures tended to phase separate, probably due to depletion-flocculation mechanisms. Ternary phase diagrams have been established according to the biopolymer concentrations. The rheological properties of these mixed systems have been investigated in the monophasic domain, as well as in the biphasic one. Modifications of the flow and the viscoelastic properties with respect to the individual components were clearly evidenced in the two-phase domain. The ultrastructure of the guar gum-micellar casein mixtures has been described using confocal laser scanning microscopy. In the biphasic domain, observations of the mixed system at concentrations corresponding to those of rheological measurements clearly evidenced that the phase separation process has yielded a continuous network mostly composed of the aggregated micellar casein. (C) 1998 Elsevier Science Ltd. All rights reserved.
\end{abstract}

\section{Introduction}

Biopolymer mixtures are widely used in the food industry because they impart a desirable texture to foodstuffs. They occur very often in dairy products in which casein constitutes indeed the major protein component (Swaisgood, 1982). Therefore, the knowledge of the mechanisms occurring in casein-polysaccharide mixed systems is of great importance in order to develop specific properties in dairy products.

Casein micelle is a relatively large entity and has a rather complex structure (diameter between 20 and $600 \mathrm{~nm}$ ) (Schmidt, 1982). This colloidal assembly is a supramolecular association of individual casein subunits: $\alpha_{\mathrm{s} 1}, \alpha_{\mathrm{s} 2}, \beta$ and $\kappa$ caseins. These fractions are organized within the micelle according to their hydrophobic and hydrophilic groups, yielding submicelles; $\kappa$ casein is the most hydrophilic fraction and therefore is thought to be mainly present on the surface of the micelle, providing a sterically stabilizing outer layer (Visser, 1992). The submicelles are held together by colloidal calcium phosphate (Van Dijk, 1990). This

\footnotetext{
* Corresponding author.
}

implies that the micelle is in dynamic equilibrium with its ionic environment (Holt, 1992; Visser, 1992) and is a very large and physically stable entity.

Galactomannans are seed polysaccharides, most widely used in the food industry as thickening agents. They have a linear backbone of (1-4) linked $\beta$-D-mannose residues substituted with side chains constituted by single (1-6)- $\alpha-\mathrm{D}$ galactose residues (Dea \& Morrison, 1975). Guar gum, which is the most widely used galactomannan has a mannose to galactose ratio of about 1.8. Galactomannans are known to exhibit the behaviour of a macromolecular solution, the properties of which are governed by topological entanglements (Robinson et al., 1982; Clark \& Ross-Murphy, 1987).

The behaviour of protein-polysaccharide mixtures has been the subject of a considerable number of investigations. As many as 80 protein-polysaccharide-water ternary systems have been described by Tolstoguzov $(1986,1991)$. Polymer demixion, due to thermodynamic incompatibility, is a general tendency exhibited by numerous ternary systems (polymer 1/polymer 2/solvent) involving either synthetic polymers or biopolymers. Very few studies however have been carried out on micellar casein-polysaccharide mixtures. Moreover, 
these dealt mostly with the specific casein-carrageenan mixtures (Drohan et al., 1997; Langendorff et al., 1997). Some other casein systems have been described but only when casein fractions were implied either with carrageenans (Snoeren et al., 1975; Snoeren, 1976) or with other polysaccharides (Antonov et al., 1980).

The aim of the present study was (i) to understand the physico-chemical interactions between micellar casein and a neutral food polysaccharide from a general point of view and (ii) to characterize the behaviour of the mixtures. For this purpose, guar gum was chosen as a model of a food neutral polysaccharide. In addition to rheological measurements, the structure of the systems was observed by Confocal Laser Scanning Microscopy (CLSM) and the phase diagrams of the mixtures were established according to classical procedures.

\section{Materials and methods}

\subsection{Materials}

Micellar casein (MC) was a native calcium phosphocaseinate sample purified by ultrafiltration and then freeze-dried. This was kindly supplied by Laboratoire de Recherches et de Technologie Laitière (INRA Rennes, France) and was prepared by P. Schuck. It had the following characteristics : total protein content $90.7 \%$; non casein protein $5 \%$; lactose $0.5 \%$; salts $8.3 \%$.

The guar gum sample (GG) was provided by Systems Bio Industry (France). Its intrinsic viscosity was $12.9 \mathrm{dl} /$ $\mathrm{g}$ in $0.25 \mathrm{M} \mathrm{NaCl}$ at $20^{\circ} \mathrm{C}$.

\subsection{Preparation}

Micellar casein $(10 \%)$ was dispersed in $0.25 \mathrm{M} \mathrm{NaCl}$, at $20^{\circ} \mathrm{C}, \mathrm{pH} 7$, by stirring with a paddle at $1300 \mathrm{tr} / \mathrm{min}$ for $5 \mathrm{~min}$ and then sonicated for $8 \mathrm{~min}$ at $50 \mathrm{~W}$. It was checked that this process allowed one to disperse casein micelles without any rupture neither of the micelle nor of its macromolecular components. The particle size distribution was checked using a Malvern Mastersizer IP laser granulometer. The average diameter was $0.30 \mu \mathrm{m}$, which is in agreement with literature data (Schmidt, 1982; Swaisgood, 1982; Visser, 1992). Guar gum solutions $(1 \%)$ were prepared at $20^{\circ} \mathrm{C}$ in $0.25 \mathrm{M}$ $\mathrm{NaCl}$ under magnetic stirring during $1 \mathrm{~h}$ and then heated at $80^{\circ} \mathrm{C}$ during $30 \mathrm{~min}$. In order to study the effect of the molecular weight, the guar gum sample has been sonicated by means of ultrasonic waves $(40 \mathrm{~s}$ at $10 \mathrm{~W}$ ); this way, the intrinsic viscosity of the hydrolysed guar gum (HGG) was decreased down to $8.5 \mathrm{dl} / \mathrm{g}$.

The mixtures were prepared at appropriate casein/ guar gum ratios in test tubes at $20^{\circ} \mathrm{C}$ with total biopolymer concentrations below $15 \%(w / w)$.

\subsection{Methods}

Rheological measurements have been performed using a controlled strain rheometer (Rheometrics Fluid Spectrometer RFS II) in steady and oscillatory shear with cone-plate geometry (diameter $5 \mathrm{~cm}$, angle $0.04 \mathrm{rad}$, gap $50 \mu \mathrm{m}$ ) at $20^{\circ} \mathrm{C}$ after an equilibration time of $5 \mathrm{~h}$. For guar gum solution, the strain was imposed at $40 \%$, for casein suspension at $20 \%$ and the strain was taken at $10 \%$ for the mixtures. In all cases, it was checked that the strain lay within the linearity limits of the viscoelastic behaviour.

Confocal Laser Scanning Microscopy (CLSM) was performed with a Zeiss LSM 410 Axiovert microscope. CLSM was used in fluorescence mode. Micellar casein was labelled with 8-anilino, 1-naphtalene sulphonic acid (ANS) which is thought to confine into hydrophobic zones of the proteins (Fitzgerald \& Swaisgood, 1989). It is to be emphasized that ANS does not covalently bind to proteins. Therefore, there is no chemical modification of the structure of the sample as it would be the case with covalent labelling. When it is adsorbed onto proteins, ANS is fluorescent in the Ultra-Violet light. The excitation using the UV laser was performed at $364 \mathrm{~nm}$ and the emission was recorded between 450 and $497 \mathrm{~nm}$. The samples were placed between a slide and a coverslip and sealed to prevent from evaporation. Blends were examined with a water immersed $\times 40$ objective.

Phase diagrams were established according to the polymer concentrations in $0.25 \mathrm{M} \mathrm{NaCl}$, at $\mathrm{pH} 7$ and at $20^{\circ} \mathrm{C}$. The $24 \mathrm{~h}$-aged mixtures were centrifugated at $1500 \mathrm{~g}$. These conditions of centrifugation have been chosen since, by this way, a casein dispersion does not exhibit any sedimentation. Phase separation boundary was then detected only by eye since the two phases were clearly separated when phase separation occurred. The upper phase was a guar gum-rich phase while micellar casein was more concentrated in the lower phase. For the upper phase, the casein content was obtained by measuring absorbance at $277 \mathrm{~nm}$, the galactomannan concentration being determined with a refractometer. The composition of the lower phase was obtained by calculating the concentrations from the volumes.

\section{Results}

\subsection{Flow behaviour}

Fig. 1 shows the flow curves displayed by a guar gum solution at $0.2 \%$, a casein suspension at $3 \%$, a mixture containing $0.2 \%$ of guar gum and $1 \%$ of casein and a mixture containing $0.2 \%$ of guar gum and $3 \%$ of micellar casein. The casein suspension exhibited a newtonian behaviour and was slightly viscous $\left(8.910^{-3} \mathrm{~Pa} . \mathrm{s}\right)$. The guar gum solution at $0.2 \%$ was almost newtonian with an apparent viscosity of $1.810^{-2} \mathrm{~Pa} . \mathrm{s}$ at $100 \mathrm{~s}^{-1}$. 
Hence, the viscosity of the casein suspension was much lower than the viscosity of the galactomannan solution. Therefore, the properties of a guar + casein mixture have to be compared to those of guar gum by itself at equivalent concentration. In Fig. 1, it is clearly seen that the addition of casein yields dramatic changes in the behaviour of the polysaccharide. In the presence of $1 \%$ of casein (curve 3), the viscosity was slightly increased (up to $2.310^{-2} \mathrm{~Pa} . \mathrm{s}$ at $100 \mathrm{~s}^{-1}$ ) and the non newtonian character was accentuated. At a higher casein content ( $3 \%$, curve 4$)$, the change was much more pronounced (3.3 $10^{-2} \mathrm{~Pa} . \mathrm{s}$ at $100 \mathrm{~s}^{-1}$ ) and the behaviour became thixotropic, the 'up' and 'down' curves being no more superimposed. In Fig. 2, in order to show the effect of biopolymer concentration, the flow behaviour of the later mixture (curve 4) was compared to the flow behaviour of a mixture containing $5 \%$ of casein and $0.7 \%$ of guar gum (curve 5). The apparent viscosity (4.2 $10^{-1} \mathrm{~Pa} . \mathrm{s}$ at $100 \mathrm{~s}^{-1}$ ), as well as the thixotropic loop, were then increased. It appeared that the thixotropic behaviour and the increase of the apparent viscosity were much more pronounced when the total biopolymer concentration increased. From a general point of view, a synergistic effect was exhibited since the apparent viscosity of the mixture was much higher than the sum of the viscosities of the individual components of the system at the same concentrations.

\subsection{Viscoelastic properties}

Fig. 3 illustrates the viscoelastic behaviour in oscillatory shear of the same systems. As expected in the case of the one-component systems, a strong variation of the storage modulus $G^{\prime}$ and the loss modulus $G^{\prime \prime}$ with frequency, with $\mathrm{G}^{\prime}$ lower than $\mathrm{G}^{\prime \prime}$ at low frequency, and a crossover at high frequency were observed. Indeed, the

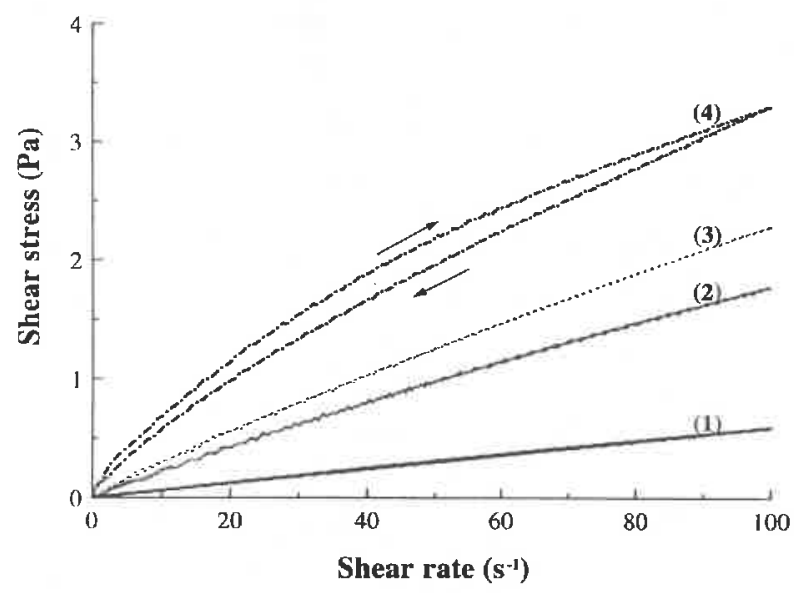

Fig. 1. Flow behaviour of a $3 \%$ micellar casein suspension (curve 1), a $0.2 \%$ guar gum solution (curve 2 ), a $0.2 \%$ guar gum $+1 \%$ micellar casein mixture (curve 3 ) and a $0.2 \%$ guar gum $+3 \%$ casein mixture (curve 4) in $0.25 \mathrm{M} \mathrm{NaCl}$.

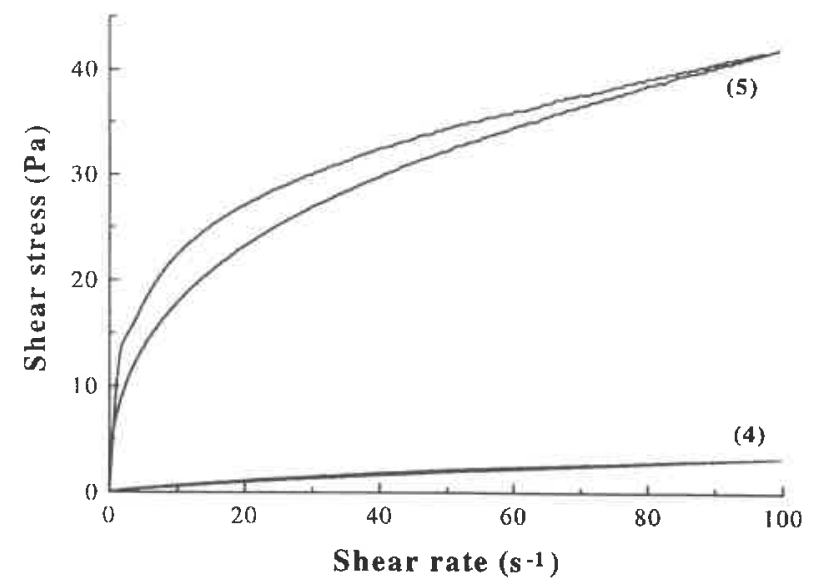

Fig. 2. Flow behaviour of a 7\% micellar casein $+0.5 \%$ guar gum mixture in $0.25 \mathrm{M} \mathrm{NaCl}$ (curve 5). Comparison with a $3 \%$ micellar casein $+0.2 \%$ guar gum mixture (curve 4 ).

viscoelastic behaviour of the galactomannan was typical of a macromolecular solution. In the case of casein, it is known that the system is closer to a suspension than to a solution. Whatsoever, both one-component systems did not evidence any organization of the medium. In contrast, the casein-guar gum mixed system $(3 \%$ casein $+0.2 \%$ guar) exhibited quite different viscoelastic properties. The viscoelastic moduli $\left[G^{\prime}(\omega)\right.$ and $\left.G^{\prime \prime}(\omega)\right]$ were much less dependent upon the frequency and their value was much higher than for guar gum alone. Moreover, although $\mathrm{G}^{\prime}$ was lower than $\mathrm{G}^{\prime \prime}$ all over the frequency range considered, the $G^{\prime}(\omega)$ curve tended to level off towards the low frequency range and to cross the $\mathrm{G}^{\prime \prime}(\omega)$ curve. This may suggest a solid-like behaviour resulting from the structuration of the medium. However, the elastic modulus of such a gel-like system appears very low (of the order of $10^{-2} \cdot \mathrm{Pa}$ ). Clearly,

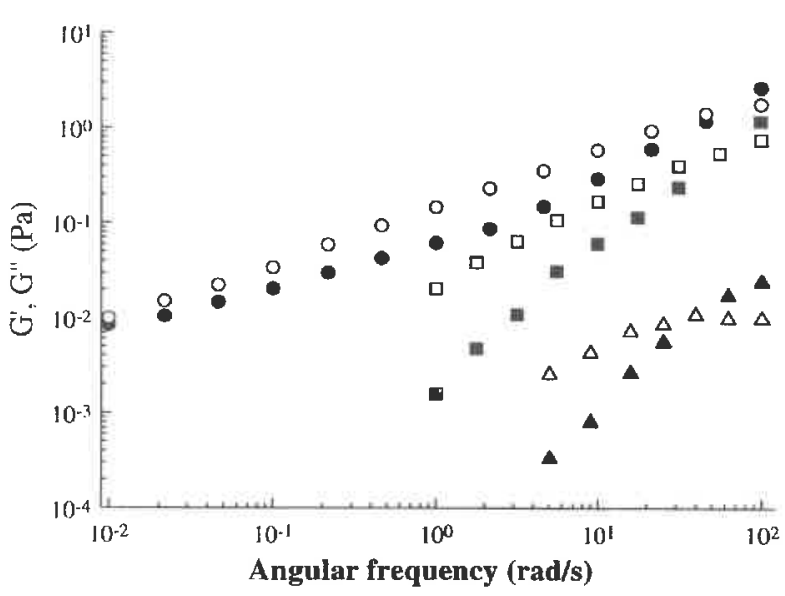

Fig. 3. Viscoelastic properties of a $3 \%$ micellar suspension (strain amplitude $20 \% ; \mathrm{G}^{\prime}: \Delta, \mathrm{G}^{\prime \prime}: \Delta$ ), a $0.2 \%$ guar gum solution (strain amplitude $40 \% ; \mathrm{G}^{\prime}: \square, \mathrm{G}^{\prime \prime}: \square$ ) and a $0.2 \%$ guar gum-3\% micellar casein mixture (strain amplitude $10 \% ; \mathrm{G}^{\prime}: 0, \mathrm{G}^{\prime \prime}: \mathrm{O}$ ) in $0.25 \mathrm{M} \mathrm{NaCl}$. 
mixing micellar casein to a galactomannan solution can result in the formation of a slightly structured system as it is evidenced in steady shear and in oscillatory shear measurements.

\subsection{Microstructure of the mixtures}

Labelling the micellar casein with ANS allowed us to localize the micellar casein in the mixture by fluorescence microscopy since guar gum is not fluorescent. Casein micelles will appear in clear in the picture owing to the fluorescence of the ANS while the dark areas will correspond to zones devoid of casein, thus containing mostly guar gum. Moreover, as CLSM is able to focus only on one plane of the sample, it means that the fluorescence of the rest of the sample does not interfere with the fluorescence of the focal plane. Therefore, CLSM gives not only high resolution information about one plane but can also indicate the three dimensional structure of the sample by superimposing different focal planes.

Fig. 4 corresponds to a focal plane of a $0.2 \%$ guar gum $+0.3 \%$ casein mixture. It is seen that fluorescence was regularly distributed in the photograph indicating that casein was spread all over the medium. The system was seen homogeneous at the scale of resolution $(>1 \mu \mathrm{m})$.

Fig. 5 shows the structure obtained by mixing $0.2 \%$ of guar gum and $3 \%$ of casein. The scale of this photograph is not the same as the previous one because the observed structures are much larger. In this mixture, the repartition of the fluorescence was not so regular. Casein was localized in areas which have a broad size distribution (from 10 to more than $100 \mu \mathrm{m}$ ). It is to be reminded that the average size of casein micelles is around $0.3 \mu \mathrm{m}$. Therefore, these large zones originate from a concentration of casein micelles. Moreover, these constitute apparently the continuous phase as evidenced by a 3-D observation performed by optical sectioning through the sample thickness (not shown here). Two phases coexisted obviously in this system, one containing mainly casein micelles whereas the other one was enriched with guar gum. This is in contrast with the previous observations where the system was one phase (Fig. 4).

\subsection{Phase diagrams}

So far, the rheological measurements as well as the microscopic observations have been performed within a time scale of $5 \mathrm{~h}$. During this period of time, the system appeared stable. From the previous microscopic observations, it is clear however that casein-guar gum mixtures can phase separate beyond a certain concentration of biopolymers. The phase diagrams were therefore established 24 hours after preparation and a subsequent centrifugation in order to determine the state of the mixtures whatever their initial composition.

Fig. 6 illustrates the main features of the phase diagram of a casein-guar gum mixture in $0.25 \mathrm{M}$ $\mathrm{NaCl}, \mathrm{pH} 7$ and $20^{\circ} \mathrm{C}$. The binodal (solid curve) separates the one-phase region from the two-phases region and was built by direct observation of the phase separation in the test tubes (points 0 ). Upon mixing the two macromolecular systems well beyond the binodal (points $\mathbf{A}$ ), it was possible to draw the tie-lines (dotted lines) from the respective composition of the lower phase (points $\nabla$ ) and the upper phase (points $\Delta$ ). The coordinates of the critical point were $0.8 \%$ of casein and $0.09 \%$ of guar gum. This point (symbolized by represents the composition of a system separating into two phases of the same volume and composition (Tolstaouzov, 1992). The yield point (symbolized by $\square$ ) which is defined as the lower total polymer concentration leading to phase separation corresponded to $0.4 \%$ $(0.18 \%$ of guar gum and $0.22 \%$ of casein).

Points numbered 1 and 2 corresponded to the concentrations of the systems observed by confocal microscopy, the point number 1 (under the binodal) giving the composition of a monophasic system and the point number 2 (beyond the binodal) corresponded to the two phases system. This latter point is very close to the phase inversion point, which can explain why the casein micelles constitute the continuous phase of the mixture on the Fig. 5. In order to study the effect of the molecular weight of the galactomannan on the phase separation behaviour, the guar gum sample has been sonicated. The molecular weight of the initial sample can be calculated from the intrinsic viscosity and is around $1.810^{6}$ (Robinson et al., 1982). The sonication process yielded a molecular weight of the order of $110^{6}$

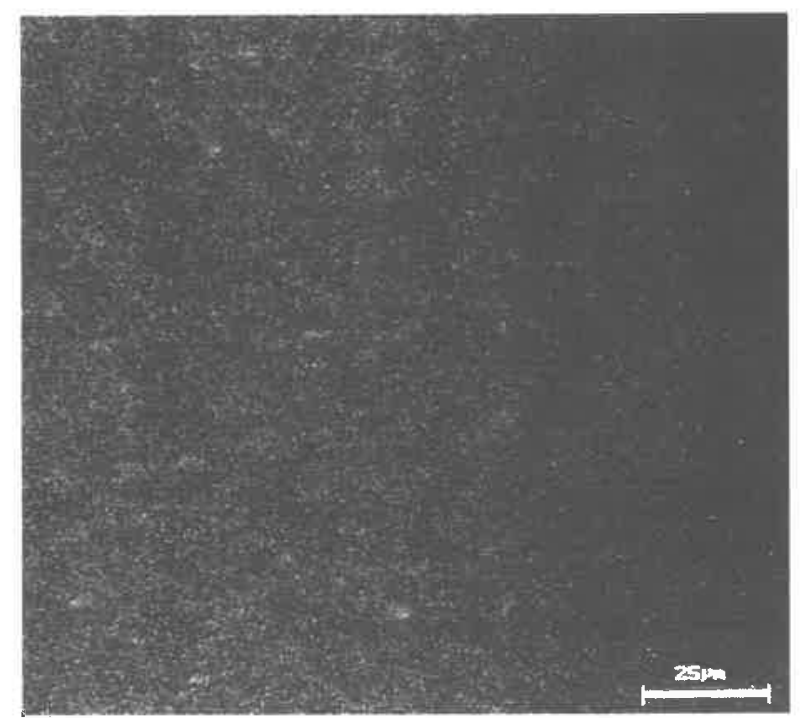

Fig. 4. Microstructure of a mixture containing $0.2 \%$ of guar gum and $0.3 \%$ of micellar casein. Observation at $364 \mathrm{~nm}$. 
which corresponded to a depolymerization of $40 \%$. Fig. 7 shows the casein-guar gum binodal compared to the casein-HGG one. In the presence of the depolymerized guar gum, the binodal was shifted towards a higher polysaccharide concentration than in the case of the initial guar gum sample. However, the lower total biopolymer content leading to phase separation remained at $0.4 \%(0.22 \%$ of casein and $0.18 \%$ of depolymerized guar gum).

\subsection{Rheology of casein-enriched phases}

In order to understand the properties of the mixture before the phases have separated at the macroscopic level, we compared the properties of the casein-enriched phase with that of the original mixture. In Fig. 8, the

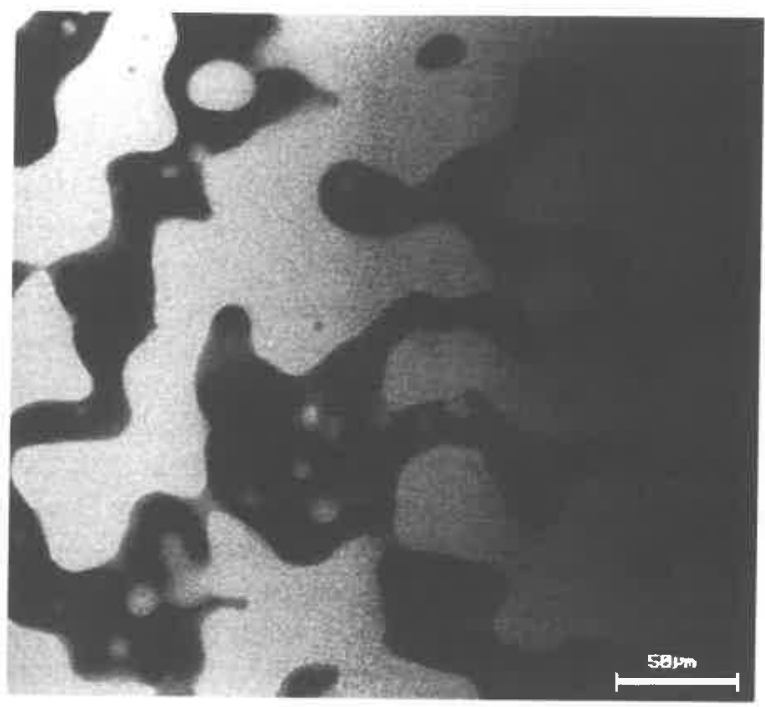

Fig. 5. Microsturcture of a mixture containing $0.2 \%$ of guar gum and $3 \%$ of micellar casein. Observation at $364 \mathrm{~nm}$.

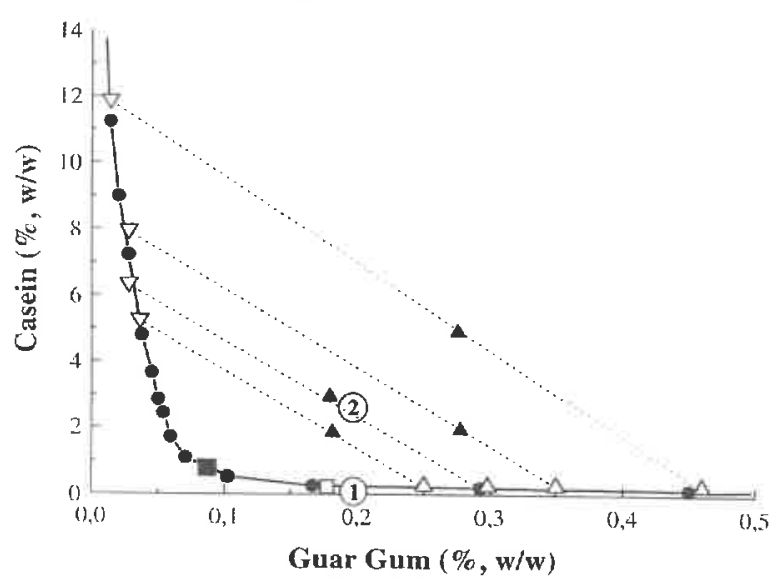

Fig. 6. Phase diagram of the casein-guar gum mixture $(0.25 \mathrm{M} \mathrm{NaCl}$, $\mathrm{pH} 7,20^{\circ} \mathrm{C}$ ) Binodal (solid curve. points $)$; tie lines (dotted lines); initial mixtures $(\boldsymbol{\Lambda})$; upper phase $(\Delta)$; lower phase $(\nabla)$; critical point (匹); threshold point ( $\square$ ) flow curve exhibited by the initial mixture with composition of Fig. 5 ( $3 \%$ casein, $0.2 \%$ guar gum) (curve 4 ) is shown together with that of the casein-enriched phase separated from the mixture and containing $6.5 \%$ casein and $0.03 \%$ guar gum (curve 7 ). The flow curve of a system prepared by directly mixing $6.5 \%$ casein and $0.03 \%$ guar is also shown for comparison (curve 8 ). This latter flow curve was very close to that of a $6.5 \%$ casein dispersion (curve 6). The only difference between these two last curves could be ascribed to the presence of a low amount of guar gum which increased slightly the viscosity of the system. In contrast, curve 7 which is the flow curve of the casein-enriched phase of the same composition differed dramatically from curve 6 . The viscosity of the system was much higher than the one of the initial mixture and obviously than the one obtained upon mixing directly $6.5 \%$ casein with $0.03 \%$ guar. This

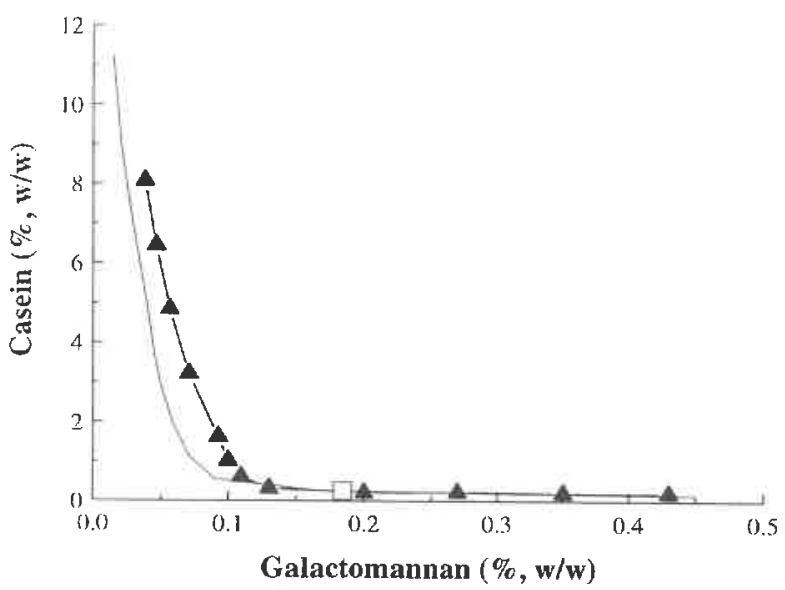

Fig. 7. Phase diagram of the micellar casein-hydrolysed guar gum mixture ( $\mathbf{A})\left(0.25 \mathrm{M} \mathrm{NaCl}, \mathrm{pH} 7,20^{\circ} \mathrm{C}\right)$; threshold point $(\square)$. Comparison with initial Guar gum (solid curve).

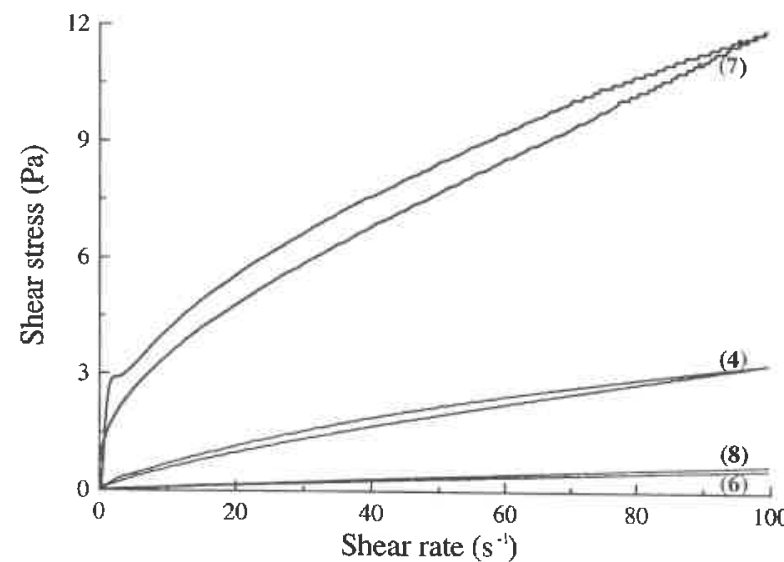

Fig. 8. Flow behaviour of a $0.2 \%$ guar gum $+3 \%$ micellar casein mixture (curve 4), a $6.5 \%$ micellar casein suspension (curve 6), the lower phase of the previous mixture containing $6.5 \%$ of micellar casein and $0.03 \%$ of guar gum (curve 7 ) and a $6.5 \%$ micellar casein + $0.03 \%$ guar gum mixture (curve 8 ). 
clearly illustrates the structuration of the casein-enriched phase as a result of the phase separation process.

\section{Discussion}

The rheological data show that the behaviour of the mixed system differs significantly from that of individual components. A transition from the behaviour of a macromolecular solution to that of a slightly structured system was observed when casein was added to guar gum. On the basis of microscopic observations, this particular behaviour is undoubtedly related to a phase separation phenomenon. When dealing with phase separation in mixed polymer systems, thermodynamic incompatibility is the more generally evoked mechanism. However, when spherical particles are implied, phase separation may also arise from depletion-flocculation phenomena. Thermodynamic incompatibility implies volume exclusion between polymer species which requires that macromolecules have been individualized and hence solubilized. This is related to the entropy of the system and arises from the fact that the free energy of mixing is minimized (Flory, 1942). Many mixed biopolymer systems exhibit phase separation through this mechanism. In the case of depletion-flocculation, on the other hand, the stability of a particulate suspension is depressed by the addition of a polymer (Williams \& Smith, 1995). This mechanism has been initially described by Asakura and Oosawa in the case of a suspension of hard spheres in the presence of macromolecules (Asakura \& Oosawa, 1954, 1958). This theoretical treatment explains how a dispersion of particles can be flocculated by the exclusion of a polymer molecule from the space between close spheres. The result is a difference in polymer concentration between the interparticle space and the outside regions surrounding the particles. The osmotic pressure of the bulk polymer solution is therefore greater than in the excluded zone containing pure solvent. Particles are pushed together owing to the additional attractive osmotic force generated between particles. This force depends on the size and shape of the polymer molecules. Calculations of interaction potentials should allow one to theoretically describe these mechanisms on the basis of the total potential energy combining London-van der Waals attraction, electrostatic repulsion, steric repulsion, and depletion attraction. This can be attempted using the theoretical approach developed by Asakura and Oosawa $(1954,1958)$ on the basis of a simple geometrical analysis. However, only a qualitative description can be yielded due to the simplistic basic assumptions not taking into account several parameters such as the deformability of particles or the molecular weight distribution of the polymer. This mechanism has been described in detail in the case of dispersions of solid particles (latex particles, silica) in the presence of polysaccharides (Gast et al., 1986; Hörner et al., 1997; Otsubo, 1996; Patel \& Russell, 1987, 1988; Snowden et al., 1994). The same mechanism was observed in the case of the addition of non-adsorbing polysaccharides to protein-stabilized emulsion (Cao et al., 1991).

Casein micelles are organized in large supramolecular entities which can be considered as spherical particles. They are covered by $\kappa$-casein, which stabilizes them in the suspension through steric and electrostatic repulsions. Moreover, the hairy surface prevents neutral polymers from adsorbing on the micelles. A dispersion containing micellar casein is therefore closer to a particulate suspension than to a macromolecular solution. Although a phase separation through thermodynamic incompatibility can not totally be ruled out, depletion-flocculation is more likely involved in the mechanism. When guar gum chains are added to the casein suspension, they would be excluded from the space between the micelles, provided the casein concentration is high enough. The energetic barrier would be then crossed over, leading to the aggregation of the micelles. The flocs of casein micelles would tend to self aggregate and form a network, which would constitute the continuous phase of the system as it is shown by the CLSM observations. This explains why we experienced an increase in the viscosity of the medium and a change in the viscoelastic properties. Moreover, since HGG has a lower molecular weight than the initial guar gum sample, it occupies a smaller volume in the medium than the guar gum chains. The exclusion of the polymer occurs thus to a lesser extent, resulting in a decrease of the aggregation of the particles at the same concentration and therefore a shift of the binodal towards a higher polysaccharide content (Fig. 7). Unfortunately, it is very difficult to extend theoretical calculations of energetic potentials for hard spheres to the case of micellar casein because of the very complex structure of the casein micelles (Payens, 1977). A simple way to confirm that the particles are weakly flocculated is to dilute an aggregated sample (Patel \& Russell, 1989; Prestidge \& Tadros, 1988); the return to one phase upon dilution indicates that the flocculation process is reversible; this reflects the weakness of the interparticle forces which is expected from this mechanism. The rheological behaviour of the mixed system is reminiscent of that exhibited by a dispersion of particles flocculated by a polymer such as latex particles in the presence of polysaccharides (Patel \& Russell, 1987, 1989). This is reflected by the existence of a plateau modulus at low frequency which, although very low, is indicative of a network stabilized by weak interactions. This network can be easily broken down under shear as evidenced by the thixotropic behaviour owing to the weakness of these interactions. Depending upon the composition of the initial mixture, the rheological behaviour of the systems obtained just 
after preparation will be governed by the continuous phase which would be either guar-enriched or caseinenriched. Hence, in the case of the composition shown in Fig. 5 (3\% casein, $0.2 \%$ guar), from the phase diagram we know that upon separation the casein-enriched phase will contain $6.5 \%$ casein and $0.03 \%$ guar gum while the guar-enriched phase will be composed of $0.3 \%$ guar gum and $0.02 \%$ casein. From the tie-line, the volume ratio of the respective phases will be $55 \%$ for the guar-rich phase and $45 \%$ for the casein-enriched one. The question then arises as to whether the continuous phase during rheological measurements is the guar-enriched or the casein-enriched one. Although we are unable to know exactly the respective compositions of the two phases in the mixture at the time when rheological measurements are performed, it is evident that they would tend to that of the separated phases. From Fig. 5, the casein-rich phase appears continuous. Moreover, it is clearly seen from Fig. 8 (curve 7) that this latter phase is strongly organized likely due to the flocculation process in agreement with what has been previously reported in the case of latex-dextran systems (Patel \& Russell, 1987). Therefore, it may be postulated that the rheological behaviour of this mixture is governed by a network of flocculated casein, the galactomannan-enriched phase contributing to a much lesser extent to the rheology of the flocculated system.

It is to be emphasized that the casein content of the mixture shown in Fig. 5 is close to the composition of milk ( $\sim 3 \%$ casein). It is therefore expected that the phenomena reported here would be also observed upon mixing guar gum to milk. An immediate increase in the viscosity of the system will be experienced due to the thickening properties of guar gum. However, the phase separation process would actually take place and the system would appear unstable after a delay.

\section{Acknowledgements}

Financial support to one of the authors (S. Bourriot) from the Institut CANDIA (France) is gratefully acknowledged.

\section{References}

Antonov, Y. A., Grinberg, V. Y., Zhuravskaya, N. A., \& Tolstoguzov, V. B. (1980). Journal of Texture Studies, 11, 199-215.
Asakura, S., \& Oosawa, F. (1954). J. Chem. Phys., 22, 1255-1256.

Asakura, S., \& Oosawa, F. (1958). Journal of Polymer Science, 33, 183-192.

Cao, Y., Dickinson, E., \& Wedlock, D. J. (1991). Food Hydrocolloids, $5,443-454$

Clark, A. H., \& Ross Murphy, S. B. (1987). Adv. Polym. Sci., 83, 55192.

Dea, I. C. M., \& Morrison, A. (1975). Adv. Carbohydr. Chem. Biochem., 31, 241-312.

Drohan, D., Tziboula, A., Mc Nulty, D., \& Horne, D. S. (1997). Food Hydrocolloids, 11, 101-107.

Fitzgerald, R. J., \& Swaisgood, H. E. (1989). Archives of Biochemistry Biophysics, 268, 239-245.

Flory, P. J. (1942). J. Chem. Phys., 10, 51-61.

Gast, A. P., Russel, W. B., \& Hall, C. K. (1986). J. Coll. Interf. Sci., $108,161-171$.

Holt, C. (1992). In C. B. Anfisen, J. T. Edsall, F. M. Richards, \& D. S. Eisenberg (Eds.), Advances in protein chemistry (Vol. 43, pp. 63151). London: Academic Press.

Hörner, K. D., Töpper, M., \& Ballauff, M. (1997). Langmuir, 13, 551558.

Langendorff, V., Cuvelier, G., Launay, B., \& Parker, A. (1997). Food Hydrocolloids, 11, 35-40.

Otsubo Y. (1996). Heterogeneous Chem. Rev., 3, 327-349.

Patel, P. D., \& Russel, W. B. (1987). J. Rheol., 31, 599-618.

Patel, P. D., \& Russel, W. B. (1988). Colloids and Surfaces, 3I, 355383.

Patel, P. D., \& Russe1, W. B. (1989). J. Colloid Interface Sci., 131, 201210.

Payens T. A. J. (1977). Biophys. Chem., 6, 263-270.

Prestidge, C., \& Tadros, Th. F. (1988). Colloids and Surfaces, 31, 325346.

Robinson, G., Ross-Murphy, S. B., \& Morris, E. R. (1982). Carbohydrate Research, 107, 17-32.

Schmidt, D. G. (1982). In P. J. Fox (Ed.). Developments in dairy chemistry (Vol. 1, pp. 60-86). London: Applied Science Publishers.

Snoeren, T. H. M., Payens T. A. J., Jeurnink, J., \& Both, P. (1975). Neth. Milk Dairy J., 30, 132-141.

Snoeren, T. H. M. (1976). Thesis, Netherland Instituut voor Zuivelonderzoek, Ede, The Netherlands.

Snowden, M. J., Williams, P. A., Garvey, M. J., \& Robb, I. B. (1994). J. Coll. Interf. Sci., 166, 160-167.

Swaisgood, H. E. (1982). In P. J. Fox (Ed.), Developments in dairy chemistry (Vol. 1, pp. 1-59). London: Applied Science Publishers.

Tolstoguzov, V. B. (1986). In J. R. Mitchell, \& D. A. Ledward (Eds.), Functional properties of food macromolecules (pp. 385-415). London: Elsevier.

Tolstoguzov, V. B. (1991). Food Hydrocolloids, 4, 429-468.

Tolstoguzov, V. B. (1992). In G. O. Phillips, P. A. Williams, \& D. J. Wedlock (Eds.), Gums and stabilizers for the food industry (Vol. 6, pp. 241-266). Oxford: IRL Press.

Van Dijk, H. J. M. (1990). Neth. Milk and Dairy J., 44, 65-81.

Visser, H. (1992). In H. Visser (Ed.), Protein interactions (pp. 135165). New York: VCH.

Williams, P. A., \& Smith, N. J. (1995). In S. E. Harding, S. E. Hill, \& J. R. Mitchell (Eds.), Biopolymer mixtures (pp. 161-171). Nottingham: Nottingham University Press. 


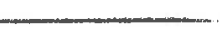

